\title{
Expectativas y limitaciones de la democracia en la Sevilla del Sexenio (1868-1874).
}

\author{
Eloy Arias Castañón *
}

\section{INTRODUCCIÓN}

Frente a las limitaciones ideológicas y políticas del régimen isabelino surgió en 1868 un relanzamiento político promovido a través de una coalición compuesta de unionistas, progresistas y demócratas en torno a un programa que tenía como puntos fundamentales el derrocamiento de la monarquía de Isabel II y el planteamiento de un nuevo sistema sustantado en la soberanía nacional y que tendría que ser definido en unas Cortes Constituyentes elegidas por sufragio universal. Se partía así de unas perspectivas liberalizadoras y éstas terminaron por asentarse a través de los programas de las juntas revolucionarias y de la presión popular que incorporaron toda una serie de reivindicaciones de libertades y derechos de los ciudadanos imponiéndose el tono democrático típico del movimiento revolucionario de $1868^{1}$.

* Universidad de Sevilla. Esta comunicación es un extracto de nuestro trabajo Republicanismo federal y vida política en Sevilla (1868-1874), Tesis de Licenciatura inédita, Sevilla 1986, se incorporan por tanto sólo algunas notas generales.

1 EIRAS Roel, A., "Nacimiento y crisis de la democracia en España: la revolución de 1868", Cuadernos hispanoamericanos, núm. 231, marzo 1969, págs. 594-627. ID., El partido demócrata español 1848-1868. Madrid, Rialp, 1961. 
Pese a todas las expectativas la apertura democrática rápidamente se mostró bastante limitada:

1. Primero porque surgía de una coalición. La preparación de la Revolución de 1868 se destaca desde luego como el resultado de la acción de unas "fuerzas complementarias", obra de colaboración ${ }^{2}$, y estas perspectivas impregnaron en principio todas las justificaciones de sus dirigentes e incluso formaron parte de la filosofía de las propias juntas pues - como dice Bozal - su doctrina básica «era el alejamiento de la actividad partidista», pretendian «representar al pueblo en su conjunto sin distingos ni matices" ${ }^{3}$. Esta actitud permitió sin duda agrupar una serie de apoyos que dieron fuerza a la coalición revolucionaria y facilitó su rápido triunfo, pero provocó como contrapartida que la solución se presentase como "pluralista al máximo", dándose "una ambigüedad esencial de su protagonización» al aliarse doctrinarios con demócratas ${ }^{4}$.

Acorde con esta heterogeneidad, los planteamientos programáticos siempre adolecieron, en mayor o menor grado, de cierta indefinición. En unos casos se trataba de unas generalidades bastante imprecisas, en otros no pasaban de ser una declaraciones democráticas epidérmicas y oportunistas ${ }^{5}$ y cuando tuvieron una orientación democrática más clara siempre se silenciaban algunas cuestiones en absoluto irrelevantes y sí llamadas a provocar grandes polémicas: la forma de gobierno, la crisis social, el tema de la descentralización, la relación con los poderes revolucionarios, etc., son algunas de ellas.

No debe extrañar por tanto que entre tal confusión de integrantes y de principios el desarrollo del 68 conllevara toda una serie de enfren-

${ }^{2}$ Comellas, J. L., Historia de España en el siglo xix. Barcelona, Carroggio, 1979, págs. 216-218. ID., "Génesis de la revolución de 1868", Atlántida, núm. 36, Madrid, 1968, págs. 531-550. Eiras Roel, A., «Nacimiento...», op. cit., pág. 32.

${ }^{3}$ Bözal, V., Juntas revolucionarias. Manifiestos y proclamas de 1868. Madrid, Edicusa, 1968, pág. 3.

4 AnDRES-Gallego, J., "La Revolución de septiembre y el Estado de la Restauración", en Historia General de España y América. Revolución y Restauración (1868-1931), t. XVI2, Madrid, Rialp, 1981, págs. 6-7. JOVER, J. M., «1868, balance de una revolución», en Política, diplomacia y humanismo popular en la España del siglo Xix. Madrid, Edicusa, 1976, págs. 360-361.

${ }_{5}^{5}$ Bozal, V., Juntas..., op. cit., pág. 42, apunta como algunas juntas no son tan liberales como su retórica da a entender. En el mismo sentido FONTANA, J., "Reflexiones sobre las causas de la revolución de 1868", en Cambio económico y actitudes políticas en la España del siglo XIX. Barcelona, Ariel, pág.126, y BERnAL, A. M., «Burguesía agraria y proletariado campesino en Andalucía durante la crisis de 1868", en La propiedad de la tierra y las luchas agrarias andaluzas. Barcelona, Ariel, págs. 131-132. 
tamientos ${ }^{6}$ que terminaron por romper esa pretendida colaboración y provocaron una selección de alternativas. Se llegó así a una institucionalización que marcaba un retroceso respecto a las expectativas revolucionarias y que derivó en una democracia impregnada de valores doctrinarios, "moderantistas» ${ }^{7}$, y frente a ella surgieron otras alternativas más radicales.

2. Y esto sin salir del más puro nivel político, superestructural, porque si nos fijamos en unas perspectivas más amplias entonces se encuentran una deficiencias de efectos aún más considerables. Como apunta J. M. Jover «la raíz de la inautenticidad del liberalismo español (no estriba)... sino en el interesado mantenimiento de un condicionamiento socioeconómico adverso al funcionamiento real de un sistema representativo" y lo mismo podria decirse de una democracia que pretendía un cambio político sin alterar prácticamente sus bases socioeconómicas $^{8}$.

Limitaciones de este tipo aparecían ya en los propios programas revolucionarios donde no se pasaba en general de proclamar la abolición de consumos y quintas y el liberalismo económico a la par que se desarrollaba de forma coyuntural un intervencionismo institucional típico de épocas de crisis y ceritrado en la oferta limitada de trabajo por medio de

${ }^{6}$ Fontana, J., «Reflexiones...», op. cit., págs. 103-104. ElRas Roel, A., «Nacimiento...", op. cit., págs. 598-606 y 623-627. ARTOLA, M., La burguesía revolucionaria 1808-1874. Madrid, Alianza, 1977, págs. 368-370. JuTGLAR, A., «La revolución de septiembre, el gobierno Provisional y el reinado de Amadeo l", en JOVER, J. M., (dir), La era isabelina y el Sexenio democrático (1834-1874), Madrid, Espasa Calpe, 1981, págs. 645-648. BERNAL, A. M., «Burguesía...» op. cit., pág. 111.

7 JOVER, J. M., «1868...» op. cit., págs. 360-361, habló del peso del «moderantismo entendido no como partido político sino como ideología liberal en la democracia del Sexenio y resaltó también cómo los revolucionarios, impregnados de una concepción jerárquica de la sociedad, habían buscado el apoyo de las élites naturales de su sociedad". CALERO, A. M., Discurso parlamentario. Monarquía y democracia en las Cortes de 1869, Madrid, CEC, 1987, pág. XIII, llamó la atención sobre que «la fundamentación teórica que los constituyentes hicieron de las facultades de la Corona están frecuentemente impregnadas de los elementos propios de la monarquía doctrinaria... y, desde luego, el estudio de la práctica política revela que la Constitución democrática se aplicó casi siempre con los mismos usos y convenciones constitucionales del período isabelino, lo que desnaturalizó el carácter democrático de la constitución». BALlBE, M., Orden público y militarismo en la España constitucional (1812-1983), Madrid, Alianza, 1983, págs. 193-223, sobre las limitaciones de las libertades democráticas.

${ }^{8}$ Jover, J. M., «Balance...», op. cit, págs. 350 y 360 . LÓPEZ-CORdón, M. V., La revolución de 1868 y la / República, Madrid, Siglo XXI, 1976, págs. 31-32, se refiere a la ausencia de medidas que cambiaran el estado social y económico del país y cómo «la carencia de reformas de base hizo muy problemática la puesta en marcha del programa político prometido". 
obras públicas y los intentos de control de los precios de algunos productos de primera necesidad.

Es lógico que a falta de unas reivindicaciones y de unas transformaciones sociales y económicas muchos autores hayan puesto en duda la existencia de una auténtica revolución ${ }^{9}$. Para J. Fontana, por ejemplo, la línea política triunfante en el 68 no supuso ninguna revolución social, sino un golpe de estado realizado por «unos políticos que habían tenido que recurrir a formulaciones y actitudes de apariencia revolucionaria para conseguir el apoyo popular y evitar un nuevo fracaso, no pretendian gran cosa más que la obtención del poder y la realización de pequeñas medidas de reforma política y económica ${ }^{10}$.

\section{UN ESQUEMA DE LA REVOLUCIÓN DE 1868 EN SEVILLA}

\section{a) La utopía del consenso}

En Sevilla, la coalición revolucionaria quiso hacer real su voluntad colaboracionista dejando aparte diferencias políticas en favor de la efectividad del movimiendo e intentó darle plasmación institucional organizando una Junta integrada por igual número de representantes de cada uno de los tres partidos coaligados (unionista, progresista y demócrata). Contra lo que quizá cabría esperar de esta composición, su programa adquirió unas connotaciones democráticas especialmente en el campo político que ha llevado reiteradamente a proponerlo como modelo representativo del acontecimiento de 68 . Se establece así un contraste entre ambos niveles que, aunque no permita seguir manteniendo sin más una relación directa, sí puede tener su explicación.

Desconocemos en detalle la elaboración y aprobación del manifiesto sevillano, pero la correlación de fuerzas, su evolución y el contenido del programa parecen sugerir la influencia de una actitud transaccional, ya resultado de un consenso interpartidista con el acuerdo entre unionistas,

9 Sobre las diferentes perspectivas ante el cambio social en la revolución de 1868 vid., Fuente MONGE, G. L. DE LA, "La Revolución de septiembre de 1868 en España: estado de la cuestión", en Álvarez Junco, J., (comp.), Populismo, caudillaje y discurso demagógico, Madrid, CIS.-Siglo XXI, 1987, págs. 27-72.

10 Fontana, J., «Reflexiones..." op. cit., págs. 105 y 139. 
progresistas y demócratas, ya con la imposición de una mayoría democrática resultado de la colaboración del progresismo, en muchos de sus integrantes contagiados de ese ideario, con los representantes del partido demócrata si bien cediendo en algunos postulados para poder obtener el apoyo de unionistas y de progresistas no democráticos.

Una actitud transaccional que quedaría evidenciada en la existencia de una triple limitación como mínimo dentro de la propuesta programática de la Junta sevillana. Veámoslas:

1. Las deficiencias programáticas en el campo de las transformaciones sociales de orientación popular fueron típicas - como es sabidodel juntismo del 68 y en Sevilla estuvo acorde con la orientación moderada de la democracia presente en la Junta revolucionaria que halló en la colaboración con unionistas y progresistas un contrapeso a las reivindicaciones de la democracia radical marginada y las exigencias de la masa popular.

2. Mucho más desconcertante es la ausencia de una demanda explícita de descentralización. Es este sentido el programa sevillano constituía una excepción dentro de las propuestas de tipo democrático. Teniendo en cuenta la conversión de los integrantes demócratas en republicanos federales, bien puede relacionarse dicho silencio con las negociaciones con unionistas y progresistas en la mediatización espaciotemporal del la cercanía del pronunciamiento gaditano.

3. La tercera limitación remite directamente a un entendimiento con el unionismo y quizá con el progresismo conservador. La Junta revolucionaria proclamó el «iAbajo los Borbones!», pero nada dijo respecto de su actitud hacia el duque de Montpensier. Es muy indicativo al respecto que cuando terminó la colaboración con los unionistas, los progresistas democráticos y los demócratas no dudaron en incorporar a su programa la condena del "dinastismo directo e indirecto" en una declaración de evidentes connotaciones antimontpensieristas.

Resulta difícil como puede observarse delimitar claramente el contenido transacional del programa citado, pero si las diferencias no surgieron desde el mismo principio, desde su aprobación, lo cierto es que su puesta en marcha exigida por una presión popular y una radicalización política ávidas de dar contenido a la revolución, provocó tal proceso de divergencias y de enfrentamientos que hizo inviable cualquier entendimiento. La descomposición de la coalición revolucionaria sería su resultado final. 


\section{b) La ruptura de la coalición revolucionaria}

La conflictividad política y social hizo evidentes las contradicciones de la coalición revolucionaria. Desde la perspectiva política la voluntad de consenso no dejaba de desarrollarse en un contexto de tensiones partidistas resultado de una colaboración coyuntural que debía replantearse con la convocatoria de Cortes Constituyentes por sufragio universal, y a este proceso de acercamiento/enfrentamiento se sumaban las peticiones populares de una junta elegida por sufragio y la organización y armamento de la milicia ciudadana. En ambos casos se producia una confluencia hacia la necesidad de una clarificación del programa democrático, bien para diferenciar opciones políticas cara a unas futuras elecciones en un tiempo en que casi todo el mundo se hacía pasar por demócrata, ya para organizar unas instituciones que fueran garantía suficiente para la defensa de dichos principios.

La orientación democrática revolucionaria encontraba, sin embargo, sus límites en una conflictividad social centrada en los problemas de la propiedad, en las relaciones laborales (demanda de trabajo y subida de salarios) y en la reducción de los precios de los productos de primera necesidad. No era la perspectiva de una revolución social la de los dirigentes juntistas sino la de un reformismo político, de una acción legal, para lo cual veían necesario la colaboración de los sectores políticos y sociales conservadores (unionistas y progresistas).

En este proceso de colaboración/diversificación entre las necesidades de colaboración con estos sectores y la búsqueda del apoyo popular, los demócratas intentaron hallar una fórmula que sirviera como petición de confianza en su voluntad revolucionaria, que no fuera demasiado peligrosa, es decir que no llevara a la revolución social, y que produjera las menos divergencias políticas posibles. Y la hallaron en la fórmula tradicional del anticlericalismo ${ }^{11}$, pero el acuerdo fue inviable. Los intentos de conciliar los intereses conservadores con las peticiones populares terminaron con una primera fisura en la coalición revolucionaria que quedó evidenciada con la renovación de la Junta mediante proceso electoral ${ }^{12}$.

11 Aplicamos la hipótesis lanzada por Andrés-Gallego, vid. de este autor; «La legislación religiosa en la revolución española de 1868 (periodo constituyente)" en lus Canonicum XVII, núm. 33, 1977, págs. 257-301. ID.: “La Revolución... ", op. cit., pág. 14 ID.: "Las Juntas revolucionarias de 1868. Una interpretación", en Boletín de la Real Academia de la Historia, t. CLXXVI, Madrid, 1979, págs. 39-95.

12 Durán Pastor, M., Repercusiones de la Revolución de 1868 en Mallorca. Palma de Maliorca, 1980, pág. 11, referido al caso de su análsis dice que «atención especial merece la quiebra de la unidad que proclamó el pronunciamiento a partir del mismo momento en 
La formación de una nueva Junta revolucionaria a mediados de octubre supuso un cambio en el reparto de fuerzas con el retraimiento y marginación del unionismo, una minoría progresista y el dominio mayoritario del partido demócrata. Éste pretendió seguir con la política colaboracionista dejando la posibilidad de una mayoría exclusivista en beneficio del entendimiento con el progresismo en torno al programa de septiembre y la libertad de cultos en primer lugar, lucha legal (no armada) y un "antidinastismo tanto directo como indirecto". Las posibilidades de acción de esta vía fueron, sin embargo, bastante limitadas. Se desarrollaba en la coyuntura adversa de las presiones gubernamentales en favor de la disolución juntista, y el retraimiento unionista junto con el reparto desequilibrado de fuerzas entre progresistas y demócratas revelaba un consenso bastante artificioso que convertía a la Junta en un instrumento de partido incumpliendo con ello de los principios básicos de la funcionalidad juntista, dificultando cualquier planteamiento reformista y promoviendo en cambio los revolucionarios (cómo sino se iba a obtener la colaboración necesaria del unionismo retraído y del progresismo paulatinamente distanciado para acometer una empresa que se definía como regeneración nacional y por tanto apartidista).

La situación se complicó, además, con la persistencia de la problemática social. El día 19 de octubre Sevilla fue recorrida por una manifestación de obreros, jornaleros y mujeres demandando trabajo, subida de salarios y reducción del precio del pan. El movimiento fue rápidamente controlado pero ello no impidió que se produjera una exacerbación de la problemática burguesa del orden que tuvo sus consecuencias. La colaboración entre progresistas y demócratas terminó por romperse del todo y la Junta aprovechó el cese de la Junta madrileña y las órdenes del Gobierno en el mismo sentido para disolverse el día 20 de octubre. Algunos demócratas pudieron pensar en su continuación, pero esto hubiera supuesto poco menos que una rebelión anticentralista que en el contexto de la conflictividad existente hubiera dado alas sin duda a la revolución social, y prefirieron dejar bien asegurada la propiedad y el orden ${ }^{13}$.

que se inicia el planteamiento electoral para la consolidación de las juntas y más adelante «las elecciones... configuraron un organismo que acusó enseguida la falta de homogeneidad tan proclamada el día del alzamiento" (pág. 135).

${ }^{13} \mathrm{Ya}$ se ha llamado reiteradamente la atención sobre el influjo de la crisis social en el replanteamiento de la revolución. Vid.: JUTGLAR, A.: «Fenomenología social de la Revolución", Revista de Occidente, núm. 67, Madrid, 1968, págs. 116-145. BERNAL. A. M.: «Burguesía... ", op. cit., pág. 132 se refiere al cambio de actitud de los propietarios ante el problema de la tierra. Bahamonde MAGRo, A. y TORo MÉRIDA, J., Burguesia, especulación y cuestión social en el Madrid del siglo XIX, Madrid, Siglo XXI, 1978, habla de como "ante la 


\section{LA VÍA POLITICA: EL REFORMISMO DEMOCRÁTICO}

La disolución de la Junta supuso el final de la coalición revolucionaria en Sevilla. Tras la primera ruptura entre unionistas de una parte y progresistas y demócratas de la otra, se llegaba a la segunda con el distanciamiento entre progresistas y demócratas. Se cerraba con ello un periodo de concentración, de colaboración apartidista de fuerzas heterogéneas en torno a un programa de ambigüedad democrática para dar paso a una etapa de delimitación partidista y programática. La revolución era sustituida por la política y quedaba legitimada la organización y promoción de las diferentes tendencias políticas con la vista puesta en las elecciones prometidas.

\section{A) La democracia tutelada}

La orientación democrática siguió imperando como marco general pero sus dirigentes eran conscientes de que aquélla no surgía de la nada, de que era necesario un período de preparación. Son muy significativos en ese sentido los intentos por mantener la coalición revolucionaria y de retrasar los procesos electorales. El propio Gobierno aportaba una justificación al considerar que "era preciso aguardar a que fueran sucesivamente calmándose la exaltación de la lucha y los transportes de la victoria... era preciso que los partidos llamados a intervenir en el desenlace de la presente crisis adoptaran una organización definitiva y elaborasen y dieran a conocer su símbolo", era necesario igualmente el desarrollo de las diferentes libertades para que sirviesen de garantía ${ }^{14}$.

Reflexiones similares habian sostenido las juntas revolucionarias al oponerse a la petición de que la forma de gobierno se designase mediante un plebiscito, argumentando que éste, «sin ser precedido de madura deliberación es más la expresión de la voluntad inconsciente del pueblo que de la voluntad racional de la nación, verdadera fuente de la Soberanía», que las decisiones deben ser ilustradas para «llegar a ser la

\footnotetext{
aparición de la crisis, la burguesía madrileña toma una actitud homogénea, por encima de consideraciones políticas en defensa del orden social, de la propiedad" (pág. 57).

${ }_{14}$ Gaceta de Madrid 7-XII-1868 (Convocatoria de Cortes Constituyentes, Madrid 6 de diciembre de 1868).
} 
genuina y consciente expresión de la soberanía nacional», de que «el sufragio sea consciente para ser libre». Perspectivas que concluían con la aseveración de que "correspondía únicamente a la deliberación de las Cortes constituyentes... la cuestión fundamental de la forma de gobierno, sin que se entienda que por esto se intente, siquiera, menoscabar el derecho que todo español tiene, cualesquiera que sean las funciones públicas que ejerza, para emitir su opinión, o significar sus simpatías individuales, exentas de todo carácter oficial" ${ }^{15}$.

Este tipo de consideraciones podían partir de la mejor voluntad, del reconocimiento de unas necesidades básicas para una época de tránsito y de construcción de un nuevo régimen, pero su interpretación pragmática falsificaba su espíritu. La debilidad de la coalición revolucionaria y su rápida politización impidieron una institucionalización sólida según los nuevos principios y a falta de ésta se organizaron con reminiscencias del pasado. La tutela necesaria en una época de excepción se mantuvo en época de normalidad y resultó una democracia tutelada.

El Gobierno Provisional aprovechó su manifiesto «a la Nación" para emitir su opinión en favor de la monarquía justificándola en consideraciones tradicionales («los pueblos que cuentan con larga vida, que tienen antecedentes orgánicos indestructibles, que forman parte de una comunidad de Naciones y que no pueden de repente, por medio de una transición brusca y violenta, torcer el impulso secular al cual obedecen en su marcha») y pragmáticas ("el mal éxito que han tenido tentativas de esta naturaleza en otros países de Europa") ${ }^{16}$, y la democracia comenzaba por tanto construyéndose de arriba abajo aunque se hable de respetar la soberanía nacional, acto a posteriori. Esta actitud se completaba además en la convocatoria a Cortes constituyentes donde se decía que «el Gobierno será neutral, pero no excéptico", es decir, "hará que sean profundamente respetadas y libremente expresadas todas las opiniones, pero no puede ni debe ocultar que él también tiene y utiliza el derecho de profesar la suya" ${ }^{17}$.

Esta filosofía "del poder neutral pero no excéptico" no fue sin embargo una exclusiva del Gobierno, sino que impregnó buena parte de la práctica política del momento independientemente de su tendencia. En

${ }^{15}$ Gaceta de Madrid 18-X-1868 (Manifiesto de la Junta Revolucionaria de Madrid de 17 de octubre de 1868). Esta petición de la Junta madrileña obtuvo el apoyo de otras juntas provinciales.

${ }^{16}$ Gaceta de Madrid 26-X-1868 (Manifiesto a la Nación, Madrid 25 de octubre 1868).

17 Gaceta de Madrid 7-XII-1868 (Convocatoria de Cortes constituyentes, Madrid 6 de diciembre de 1868). 
Sevilla, las denuncias contra el triunfo republicano federal no se centraron tanto en el proceso electoral en sí cuanto en la utilización partidista de las instituciones locales dominadas por aquél para orientar en su favor la opinión pública. El hecho es claro por lo que se refiere a la Milicia ciudadana de Sevilla, que se declaró partidaria de la república federal, y también concejales y diputados provinciales de ese mismo partido influyeron en favor de sus correligionarios.

Era simplemente la herencia de unas prácticas doctrinarias de que quien tiene el poder gana las elecciones, sólo que en diciembre de 1868 y enero de 1869 el poder no era unidireccional sino plural, resultado de la coalición revolucionaria del 68 y de ahí su complejidad. Desde esta perspectiva bien podría pensarse que lo realmente trascendental no radicaba tanto en la pureza del acto electoral en sí aunque tuviera su importancia, como en el respeto por "los poderes establecidos", las diferentes fuerzas políticas que habian logrado institucionalizar la revolución y garantizar el orden público en sus respectivos ámbitos. Podría decirse hasta cierto punto que el Gobierno podia ser neutral en los ámbitos sociales y territoriales dominados claramente por otras tendencias políticas, pero que no fue excéptico en lo que entendía eran sus dominios ${ }^{18}$.

En los años inmediatamente posteriores quedó bien claro, salvo excepciones, que quien tenía el poder ganaba las elecciones. El análisis del caso ecijano nos permitió en su día trazar una evolución en el comportamiento electoral durante el Sexenio que iba desde la confusión de poderes, pluralidad de opciones y gran participación electoral en un cambio en torno a la modificación de la ley electoral hacia una simplificación orientada hacia el bipartidismo, progresiva reducción de la participación electoral y gran ductilidad ante las directrices del poder central; unas directrices que anticipaban realmente el comportamiento de la Restauración ${ }^{19}$. El estudio de la gestión municipal en Alcalá de Guadaira permite hablar por otra parte de un doble mecanismo de intervención: intervencionismo orientador que revela como algunas elecciones municipales fueron precedidas de una destitución del ayuntamiento existente y nombramiento de uno interino que controla y orienta el resultado electo-

$18 \mathrm{Vid}$., Bahamonoe Magro, A., «Contribución al estudio del fraude electoral en un distrito urbano: las elecciones de 1869 en Madrid», Hispania, núm. 134, Madrid, 1978, págs. 636-660.

19 Vid., ARias Castañón, E., “Écija 1868-1874. De la revolución de 1868 a la I República", en Actas I Congreso de Historia de Écija. Écija, 1989. Aguado Higon, A. M., "Elecciones y poder burgués 1868-1874", en ExTRAMIANA, J. (dir.): Les élites espagnoles a l'epoque contemporaine. Universidad de Pau, 1982, págs. 27-40. 
ral; y de un intervencionismo corrector, desplegado por las autoridades gubernamentales en épocas críticas, que aun sin producir un cambio en la composición de las corporaciones municipales obligaba a éstas a reorientar el sentido de su gestión ${ }^{20}$.

\section{B) Las alternativas democráticas}

La disolución de la Junta revolucionaria y la ruptura de la coalición entre unionistas, progresistas y demócratas obligó a un replanteamiento de la situación política. Hubo intentos de continuar con una línea de colaboración revolucionaria pero cada opción quería orientarla en su beneficio y mientras, se iniciaba la organización y delimitación de cada partido. Al final, el panorama político sevillano quedaría fijado en tres propuestas, tres formas de entender la democracia:

\section{La Coalición monárquica}

Sustentada en Sevilla por unionistas y progresistas, especialmente con los sectores más conservadores de este partido, en torno al «Manifiesto de coalición monárquica" suscrito el 12 de noviembre en Madrid. Desde esta opción se combinaba una lectura conservadora de los principios democráticos de la revolución de 1868 con la forma de gobierno monárquica y las simpatías de buena parte de la coalición sevillana por la candidatura del duque de Montpensier. Este grupo terminó orientándose hacia el alfonsismo en unos sectores y hacia el progresismo conservador constitucional de Sagasta en otros.

\section{El progresismo democrático}

Esta tendencia se organizó partiendo del criterio de que el concepto «democrático» debía fijarse en su denominación para diferenciarles de un

20 Arias Castañón, E., "El Sexenio democrático en Alcalá de Guadaira (1868-1874)", en Actas de las II Jornadas de Historia de Alcalá de Guadaira (Sevilla). Alcalá de Guadaira, Fundación Municipal de Cultura, 1989, págs. 41-56. 
«progresismo sin progreso que se aliaba con los unionistas para obtener el apoyo gubernamental». Esta perspectiva venía a significar por una parte una reclamación de las auténticas libertades democráticas con insistencia en el tema de la libertad religiosa hasta llegar incluso al anticlericalismo, y ciertas preocupaciones populistas en torno a los temas de los consumos y quintas. $Y$ por otra parte, una monarquía popular democrática, antimontpensierista ante todo, y dispuestos al diálogo a partir de las propuestas de Espartero o de Unión Ibérica.

Constituyó un grupo bastante minoritario pero con destacadas personalidades (Antonio Machado y Núñez fue uno de sus dirigentes y llegó a ocupar el cargo de Gobernador Civil de la provincia; Nicolás María Rivero y Antonio Ramos Calderon le dieron su apoyo desde Madrid) y su trayectoria fue oscilante, en función de la coyuntura, entre una colaboración con la coalición monárquica o con el republicanismo federal, aunque siempre procuró conservar su personalidad.

Benevolentes con la monarquía de Amadeo de Saboya, terminaron por denunciar en 1871 las «influencias perniciosas de hombres doctrinarios" y las "contemporizaciones hijas de la llamada coalición" para reclamar una democracia radical inspirada en los auténticos principios democráticos y sustentada por «hombres de criterio radical dentro de la comunión monárquico-democrática" y la falta de éstos por los republicanos sensatos, ya que defenderían sus mismos principios mientras los monárquicos doctrinarios incorregibles militarían en el bando contrario, en el de la reacción. $Y$ de acuerdo con estos planteamientos tomaron la denominación de progresismo democrático radical y constituyeron uno de los puntales básicos del radicalismo de Ruiz Zorrilla.

\section{El republicanismo federal}

Surgía del seno del partido demócrata como un intento de dar profundidad al ideario democrático frente a las orientaciones un tanto formalistas con que estaba desarrollándose el 68. La democracia debía superar al liberalismo por supuesto pero también las prácticas doctrinarias en que ése se había desarrollado. Era una cuestión de ideas ciertamente pero también de garantías y así la democracia fue antimonárquica, anticlerical y antimílitarista como respuesta a la actuación de los tres puntales básicos del régimen isabelino, y se proclamó republicana, secularizadora y nacional; una república como garantía de los derechos ciudadanos, de la separación de 
poderes, de un sistema representativo de sufragio universal; una república que asegurara la separación de la Iglesia y el Estado y la libertad religiosa, y que aboliera las quintas como primer paso hacia un ejército nacional de alistamiento voluntario.

El republicanismo nacía además federal frente al centralismo liberal y como fórmula garantizadora de la representación territorial y de la limitación del poder; e iría cobrando perpectivas sociales acorde con la soberania popular y el protagonismo ciudadano.

Esta propuesta se presentó así a lo largo del Sexenio de una forma compleja, sintetizada en la acumulación de perspectivas que refleja la fórmula «democracia republicana federal social», cada una de ellas entendida de forma bien diferente y complicadas todas ellas con las diversas formas de actuación entre legalismo e insurrección y entre benevolencia o intransigencia.

Ante tal variedad de posibilidades resulta comprensible la debilidad del consenso republicano y su dificultad de articular una vía política alternativa. Las divergencias ideológicas respecto al significado de las denominaciones «federal» y "social» y su plasmación práctica terminaron debilitando todo intento organizativo. En Sevilla, estas perspectivas se hicieron evidentes primero con el fracaso de dar una organización provincial al partido, y después en la desintegración de los propios comités locales hasta llegar en la República a que el republicanismo federal carente de coordinación tuviera que utilizar las instituciones locales como sucedáneo de una organización de partido con la subsiguiente agudización de la carencia de consenso social.

\section{UNA PERIODIZACIÓN DEL SEXENIO DEMOCRÁTICO}

Teniendo en cuenta las perspectivas apuntadas se podrían establecer varias etapas en el desarrollo del Sexenio democrático en Sevilla según la siguiente división: a) de septiembre de 1868 a octubre de 1869; b) de octubre de 1869 a junio de 1872; y c) de junio de 1872 a diciembre de 1874 (véase apéndice I). 


\section{A) La herencia revolucionaria (septiembre 1868-octubre 1869)}

En esta primera etapa se planteaba - como es sabido- un nuevo régimen político en torno a la opción monárquica democrática frente a otras alternativas, la republicana federal entre ellas. No se trataba sin embargo de una mera selección de posibilidades. La elección de un sistema conllevó la liquidación de la herencia del 68 divergente de la vía oficial, y ello significaba en Sevilla el control del republicanismo federal y la anulación de su predominio en las instituciones locales. Las autoridades centrales lograron su objetivo a través de una intervención triple: 1) Disolución de la Junta revolucionaria en octubre de 1868; 2) Disolución de los Voluntarios de la Libertad en diciembre de mismo año; y 3) Destitución de los concejales y diputados provinciales republicanos y nombramiento de progubernamentales en octubre de 1869.

Desde la perspectiva republicana federal, este periodo se desarrolló con una doble vía legal e insurrecional, ambas fracasadas. En la primera comenzó obteniendo grandes éxitos electorales a nivel local al conseguir 10 de los 11 diputados a Cortes y el dominio prácticamente absoluto del Ayuntamiento sevillano así como el de otros ayuntamientos de la provincia. Su dominio político de las instituciones locales contrastó sin embargo con su minoría en las instituciones centrales y así el pretendido reformismo republicano terminó convirtiéndose en un fracaso con el consiguiente desencanto político de la masa popular republicana y la fragmentación del partido.

Frente a la crisis política los dirigentes republicanos intentaron un relanzamiento del partido en torno a los pactos federales presentados como una revitalización de la Revolución del 68 . Una propuesta que en Sevilla tuvos sus consecuencias en la tentativa de una reorganización del partido que no pudo evitar al final la utilización de la vía insurrecional con el levantamiento republicano de octubre de $1869^{21}$. La intervención del Gobierno con la utilización del ejército supuso el control del republicanismo federal y la destitución de sus representantes en las instituciones locales ${ }^{22}$. Se producía así un doble fracaso republicano y el fin de una etapa. La Revolución de 1868 había concluido.

${ }^{21}$ ARias Castañon, E, "Notas para el estudio del republicanismo andaluz: El Pacto Federal de Córdoba (1869)", en Archivo Hispalense, Sevilla, 1989 (en prensa).

${ }^{22}$ Resulta difícil determinar la extensión de esta intervención gubernamental contra el republicanismo federal en Sevilla, pero si se utilizase como criterio las elecciones municipales parciales de enero de 1870 realizadas para sustituir a los concejales destituidos así 


\section{B) La democracia conservadora (octubre 1869-junio 1872)}

Desde esta segunda etapa la unidad política-institucional se fue convirtiendo en un criterio fundamental. Ya no se aceptaba la dualidad entre instituciones centrales con monárquicos y las locales bajo dominio de la oposición republicana federal, y cuando resurgieron estas perspectivas se establecieron unas relaciones tremendamente conflictivas ante las que no se dudó en utilizar los medios que fueran para lograr el objetivo del mantenimiento de la continuidad política centro-periferia.

Después de la destitución republicana del 68 , las instituciones locales quedaron bajo dominio monárquico hasta 1871. En el Ayuntamiento sevillano esa permanencia se logró gracias a la anulación de las elecciones municipales de enero de 1870 ganadas por los republicanos federales, y su gestión llegó hasta diciembre de 1871 en que otras elecciones (anuladas en aquellos distritos donde había triunfado la oposición radicalrepublicana) permitieron el éxito del ministerialismo de turno hasta junio de 1872.

En la Diputación provincial, los nombramientos de octubre del 69 permanecieron igualmente hasta las elecciones de febrero de 1871 en las que tras duro enfrentamiento, el republicanismo federal con la ayuda de algunos monárquicos de oposición lograba imponerse por estrecho margen a los ministeriales (24 a 23). Corta existencia tuvo la nueva Corporación provincial pues en diciembre de ese mismo año se alteraba radicalmente su composición como resultado de la destitución de la mayoría y nombramiento de unos representantes que dieron el control de dicho organismo a las autoridades gubernamentales.

En cuanto a la representación de diputados a Cortes, el comportamiento aunque diferente mostraba ciertas líneas de continuidad. En 1871, las elecciones parecen reflejar la influencia de un gobierno de coalición y el reparto del poder a nivel local en un resultado en principio equilibrado, candidato único en dos distritos, enfrentamiento dual en cinco distritos y triple en otro cinco distritos (la capital y Carmona), reducción en el nivel de participación respecto a 1869 (del $74 \%$ al $64 \%$ ) fueron

como las vacantes por otras causas en aquelias localidades donde supusieran dos tercios del total de regidores, resultaría que el $38 \%$ de los ayuntamientos de la provincia, y el $41 \%$ de sus regidores, que representarían al $60 \%$ de la población estarían afectados por el cambio apuntado. Habría que conocer el número de vacantes por otras causas, pero vista la amplifud de estos datos bien podrían tomarse como criterio aproximado de la destitución republicana. 
unas características que tuvieron como consecuencia final un reparto de seis diputados ministeriales y seis republicanos federales (uno de ellos procedente del unionismo), aunque las elecciones parciales de los meses siguientes para cubrir vacantes dieron la mayoría a aquéllos. En abril de 1872 en cambio el dominio gubernamental fue claro: doce diputados frente a ninguno de la oposición coaligada de republicanos, radicales, moderados y carlistas, en medio de una escasa participación electoral.

\section{C) La democracia radical y republicana (junio 1872- diciembre 1874)}

En esta tercera etapa los mecanismos básicos utilizados fueron bastante similares a los apuntados si bien cambiaron los protagonistas conforme a la expansión republicana bajo dominio radical primero y el control republicano del poder después, y en relación con ello se utilizaron nuevas técnicas.

Así, la subida de los liberales al poder en junio de 1872 supuso la destitución de los concejales y diputados existentes para restituir en sus cargos a miembros de las corporaciones anteriormente depuestas. Se retomaba con ello la perspectiva de una revitalización de la Revolución del 68 y los republicanos volvian a dominar dichos organismos. Los procesos electorales siguientes (elecciones generales, municipales y provinciales parciales) no hicieron sino confirmar a fines de 1872 su predominio.

Con la República, la confusión y debilidad de poderes impuso procesos electorales quizá más complejos pero con un resultado muy semejante. Las elecciones generales de 1873 se caracterizaron por el enfrentamiento dual en unos distritos y dominio sin problemas de un candidato en otros con una participación electoral reducida a un porcentaje entre el 40 y el $49 \%$. Aunque la fragmentación política dificultó el consenso político sí que puede hablarse a nivel general de una bipolarización entre una mayoría benévola y una minoría intransigente, situación justamente la contraria a la de algunas instituciones locales como es el caso del Ayuntamiento sevillano. Al contraste del dominio político se sumaba pues una divergencia institucional, y estas rupturas se reflejaron en el retraimiento intransigente $y$ en el lanzamiento de un primer intento cantonalista a fines de junio de 1873. Su control y el triunfo benévolo en las municipales de julio de 1873 venían a solucionar la divergencia políticoinstitucional apuntada (territorial también podria denominarse), pero la in- 
decisión y la fragmentación de la política benevolente permitió el resurgir la vía de la insurrección cantonal lanzada por los intransigentes.

La liquidación de esa alternativa por medio de las armas y la utilización del ejército tradicional dejó bien claro que el centralismo se había impuesto. A partir de entonces y hasta fines de 1874 la composición de las corporaciones locales vino determinada por las directrices gubernamentales. 


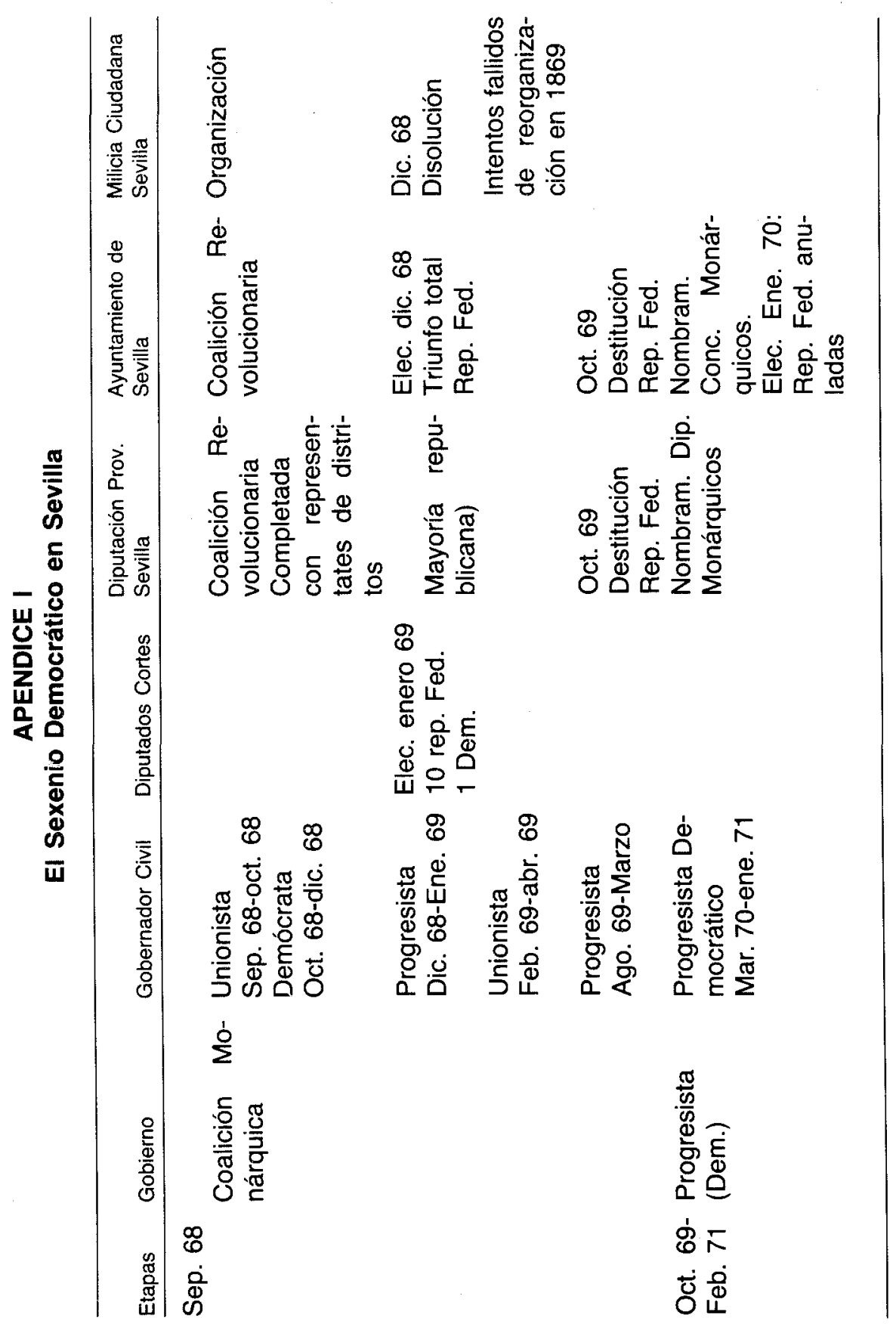



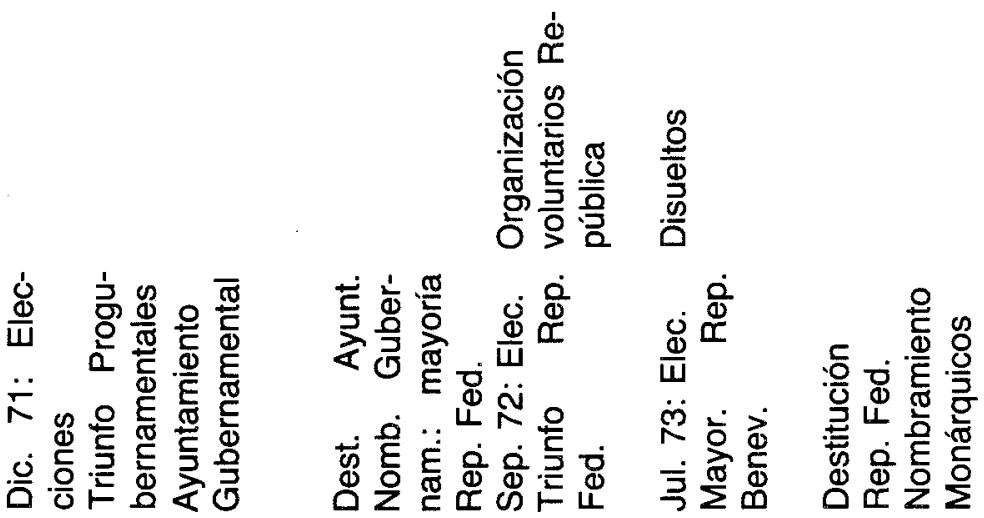

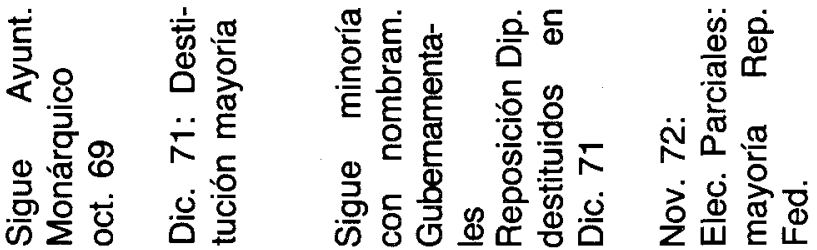

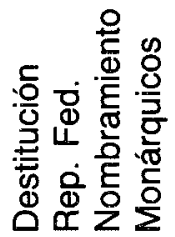

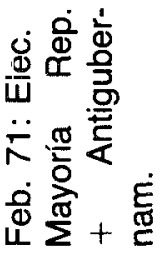

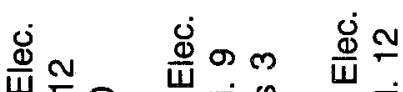

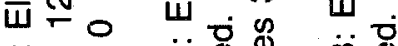

ஸ் 뒁

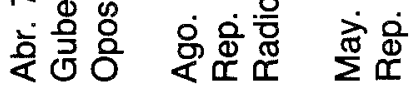

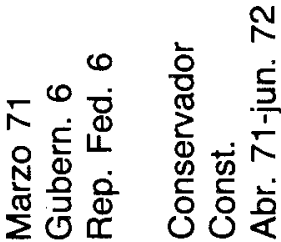

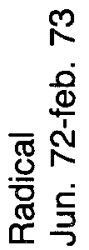

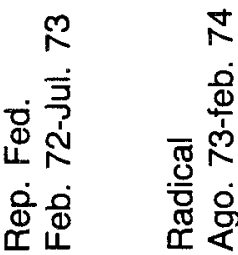

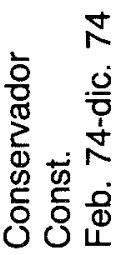

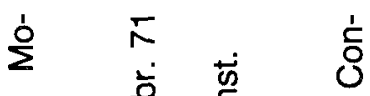

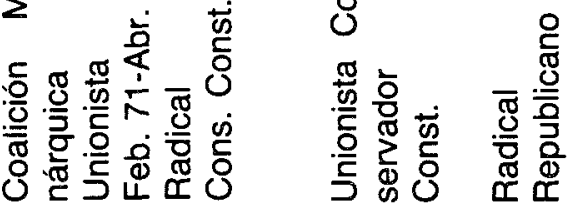

$i^{i}$

ก

这.

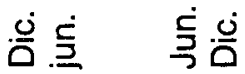

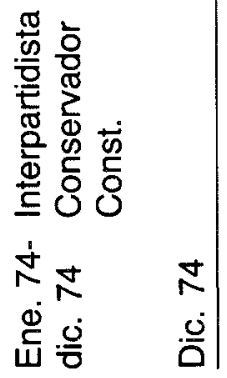

